\title{
Reevaluating the Salty Divide: Phylogenetic Specificity of Transitions between Marine and Freshwater Systems
}

\author{
(D) Sara F. Paver, ${ }^{\text {a Daniel Muratore, }}{ }^{\text {a Ryan J. Newton, }}{ }^{\text {b Maureen L. Coleman }}{ }^{a}$ \\ aDepartment of the Geophysical Sciences, University of Chicago, Chicago, Illinois, USA \\ bSchool of Freshwater Sciences, University of Wisconsin Milwaukee, Milwaukee, Wisconsin, USA
}

ABSTRACT Marine and freshwater microbial communities are phylogenetically distinct, and transitions between habitat types are thought to be infrequent. We compared the phylogenetic diversity of marine and freshwater microorganisms and identified specific lineages exhibiting notably high or low similarity between marine and freshwater ecosystems using a meta-analysis of $16 \mathrm{~S}$ rRNA gene tag-sequencing data sets. As expected, marine and freshwater microbial communities differed in the relative abundance of major phyla and contained habitat-specific lineages. At the same time, and contrary to expectations, many shared taxa were observed in both habitats. Based on several metrics, we found that Gammaproteobacteria, Alphaproteobacteria, Bacteroidetes, and Betaproteobacteria contained the highest number of closely related marine and freshwater sequences, suggesting comparatively recent habitat transitions in these groups. Using the abundant alphaproteobacterial group SAR11 as an example, we found evidence that new lineages, beyond the recognized LD12 clade, are detected in freshwater at low but reproducible abundances; this evidence extends beyond the $16 \mathrm{~S}$ rRNA locus to core genes throughout the genome. Our results suggest that shared taxa are numerous, but tend to occur sporadically and at low relative abundance in one habitat type, leading to an underestimation of transition frequency between marine and freshwater habitats. Rare taxa with abundances near or below detection, including lineages that appear to have crossed the salty divide relatively recently, may possess adaptations enabling them to exploit opportunities for niche expansion when environments are disturbed or conditions change.

IMPORTANCE The distribution of microbial diversity across environments yields insight into processes that create and maintain this diversity as well as potential to infer how communities will respond to future environmental changes. We integrated data sets from dozens of freshwater lake and marine samples to compare diversity across open water habitats differing in salinity. Our novel combination of sequencebased approaches revealed lineages that likely experienced a recent transition across habitat types. These taxa are promising targets for studying physiological constraints on salinity tolerance. Our findings contribute to understanding the ecological and evolutionary controls on microbial distributions, and open up new questions regarding the plasticity and adaptability of particular lineages.

KEYWORDS 16S rRNA, SAR11, aquatic ecology, aquatic microbiology, biogeography, environmental transitions, microbial ecology, tag sequencing

hylogenetic relationships of organisms within and across ecosystems can provide insight into the evolutionary history of lineages and how evolution might proceed into the future. Microorganisms in the water columns of freshwater and marine ecosystems provide a unique juxtaposition. On one hand, these habitats share common features of pelagic lifestyles like free-living and particle-associated niches (1), potential for interactions with phytoplankton (2), and opportunities for diverse photohetero-

Received 3 October 2018 Accepted 24 October 2018 Published 13 November 2018 Citation Paver SF, Muratore D, Newton RJ, Coleman ML. 2018. Reevaluating the salty divide: phylogenetic specificity of transitions between marine and freshwater systems. mSystems 3:e00232-18. https://doi.org/10 $.1128 / \mathrm{mSystems.00232-18.}$

Editor Theodore M. Flynn, Argonne National Laboratory

Copyright $\odot 2018$ Paver et al. This is an openaccess article distributed under the terms of the Creative Commons Attribution 4.0 International license.

Address correspondence to Maureen L. Coleman, mlcoleman@uchicago.edu.

Reevaluating the salty divide: while marine and freshwater systems have habitatspecific lineages and differ in dominant phyla they share many taxa, including "marine" SAR11 lineages 
trophic organisms, including aerobic anoxygenic phototrophs (3) and rhodopsincontaining bacteria $(4,5)$. However, salinity preference is considered a complex trait involving many genes and complex cellular integration $(6,7)$, suggesting that transitions between high and low salinity are difficult from a genetic perspective. Consistent with this idea, microbial communities from saline environments are compositionally distinct from those inhabiting nonsaline environments $(8,9)$. Salinity-induced shifts in microbial beta diversity have been observed in studies of marine-to-freshwater gradients in many systems, including the Baltic Sea $(7,10)$, Columbia River Estuary system (11), and Antarctic lakes that have become progressively less saline since becoming isolated from the sea (12). These observations of ecosystem-specific diversity support the current paradigm that transitions between marine and freshwater ecosystems are infrequent, despite many ecological similarities (13).

Environmental sequence data provide support for a "salty divide" separating marine and freshwater microbial assemblages. From a phylogenetic perspective, each clade that contains both marine and freshwater representatives includes at least one transition where a common ancestor gave rise to a daughter lineage able to survive and proliferate in a new salinity environment (13). Transitions that occurred recently are expected to result in highly similar molecular sequences recovered from marine and freshwater systems while transitions that occurred in the distant past are expected to yield habitat-specific diversification-clades that are only observed in one habitat type or the other-and a greater sequence divergence between marine and freshwater representatives (13). Prior work using phylogenetic patterns concluded that transitions between marine and freshwater environments are infrequent and most transition events occurred a long time ago in evolutionary terms $(13,14)$. For example, Logares and colleagues (14) found that within the abundant alphaproteobacterial SAR11 group, freshwater representatives belonged exclusively to a single subclade, called LD12, implying a single salinity transition from a marine ancestor to this freshwater lineage. Besides LD12, there are a number of microbial lineages that appear to be unique to freshwater lakes $(15,16)$, suggesting that these lineages do not readily colonize other habitat types. Notably, for freshwater lineages that are found in multiple habitats, the secondary habitat is most often terrestrial, not marine (16), consistent with the idea that marine-freshwater transitions are especially difficult.

Difficulty in detecting transitions between marine and freshwater systems may contribute to the paradigm that transitions occur infrequently. Detecting a transition requires sufficiently abundant extant descendants. Most immigrant cells are expected to go extinct locally due to ecological drift, just as most mutations are lost from a population due to genetic drift (17). The probability of an immigrant avoiding extinction due to ecological drift, like a mutation avoiding genetic drift, depends on the degree of selective advantage. For example, in populations of Escherichia coli $\left(\sim 3 \times 10^{7}\right.$ cells [18]), a mutation conferring a 10\% advantage appears an average of five times before it is established compared to a mutation with a $0.1 \%$ advantage which would need to appear 500 times to avoid extinction by drift (19). In addition to overcoming ecological drift, the degree of selective advantage for cells migrating between marine and freshwater habitats would need to be strong enough to overcome any salinitybased disadvantages. Microorganisms that become established must also achieve sufficiently high population abundances to be reliably detected by current sequencing methods. As amplicon sequencing data sets accumulate from an increased diversity of environments and library size increases, our ability to detect transitions improves.

Here we revisit classic questions concerning divisions between marine and freshwater microorganisms by comparing 16S rRNA V4 region amplicon sequences from available marine and freshwater data sets. This meta-analysis is timely given the accumulation of sequence data sets from diverse aquatic environments, including large lakes such as the Laurentian Great Lakes that historically have been underrepresented in sequence databases. These large lakes, sometimes referred to as inland seas, are in some ways more similar to the open oceans than to previously studied small lakes (20). Given their size, they are less influenced by their catchment than smaller lakes and 

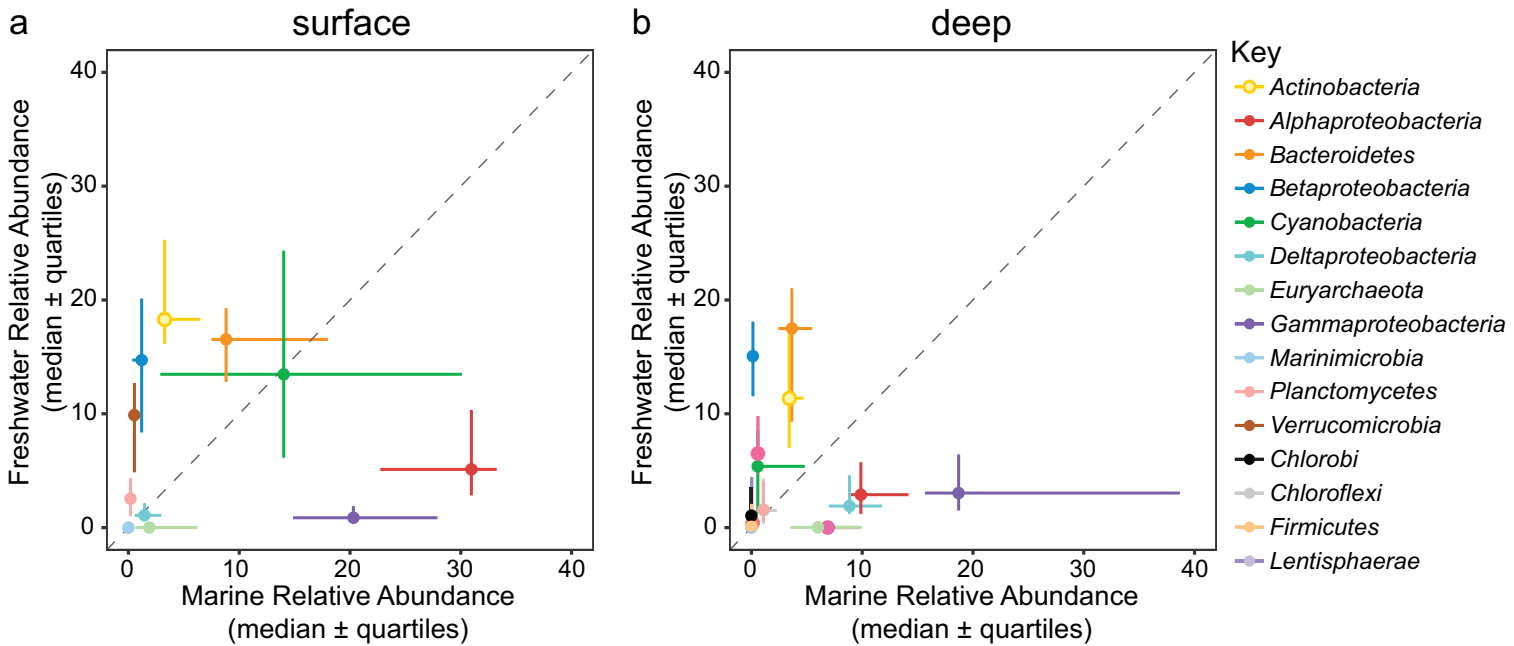

FIG 1 Median relative abundance of phyla/proteobacterial classes in freshwater and marine samples collected from surface (a) and deep (b) waters. The deepest hypolimnion (below thermocline) sample collected from stratified lakes and marine samples collected at depths $>75 \mathrm{~m}$ were classified as "deep" samples. Diagonal lines indicate a 1:1 relationship.

experience oceanic-type physical processes, including strong currents and upwelling (21). Although lakes are generally more productive than the open oceans, parts of the Laurentian Great Lakes are extremely oligotrophic, rivaling the ocean gyres in terms of phosphorus limitation and productivity (22-25). Given these features, we speculated that the Great Lakes would be more likely than small lakes to harbor lineages recently descended from marine ancestors. At a minimum, we reasoned that expanding withinhabitat diversity in our comparative analysis would improve the robustness of our conclusions between habitat types. Our specific objectives were to (i) compare the phylogenetic diversity of marine and freshwater microorganisms and (ii) identify lineages that have a comparatively high or low degree of sequence similarity between marine and freshwater ecosystems. These lineages may represent targets for exploring physiological and molecular barriers to salinity tolerance, and for identifying novel strategies for overcoming these barriers.

(This article was submitted to an online preprint archive [26].)

\section{RESULTS}

Marine and freshwater communities have distinct taxonomic composition. We first asked whether marine and freshwater communities were compositionally distinct in our combined data set, consistent with previous studies. To this end, we compared the abundances of phyla (classes for Proteobacteria), orders, and families between marine and freshwater samples. At the phylum level, Alphaproteobacteria, Gammaproteobacteria, Euryarchaeota, and Marinimicrobia had significantly higher relative abundances in marine systems while Betaproteobacteria and Verrucomicrobia had higher relative abundances in freshwater systems (Fig. 1). At finer taxonomic levels, we found that orders, and especially families, showed a positive correlation between relative abundance in freshwater and fold enrichment in freshwater versus marine samples, and vice versa; in other words, the most abundant freshwater families also appeared to be highly specific to freshwater, while numerous other families have similar abundances in marine and freshwater systems (see Fig. S1 in the supplemental material).

We next took a taxon-level approach, using minimum entropy decomposition (MED [27]) to cluster sequences into taxonomic units (i.e., MED nodes) and UniFrac distances to compare assemblages of marine and freshwater nodes. Consistent with previous studies, we found that marine and freshwater assemblages were phylogenetically distinct (Fig. S2; weighted UniFrac PerMANOVA, $F=23.6, R^{2}=0.24, P<0.001$, df $=75$; unweighted UniFrac PerMANOVA, $F=41.8, R^{2}=0.36, P<0.001, \mathrm{df}=75$ ). This result is robust even with our expanded data set, suggesting that environmental factors such as 
TABLE 1 Genera containing at least two shared MED nodes

\begin{tabular}{|c|c|c|c|c|}
\hline Phylum/class & Order & Family & Genus $^{b}$ & $\begin{array}{l}\text { No. of } \\
\text { shared } \\
\text { nodes }\end{array}$ \\
\hline Actinobacteria & Acidimicrobiales & OM1_clade & "Ca. Actinomarina" & 2 \\
\hline Actinobacteria & Acidimicrobiales & Sva0996a & Sva0996a & 2 \\
\hline Actinobacteria & Corynebacteriales & Mycobacteriaceae & Mycobacterium & 2 \\
\hline Actinobacteria & Micrococcales & Microbacteriaceae & "Ca. Aquiluna" & 4 \\
\hline Actinobacteria & PeM15 & PeM15 & PeM15 & 4 \\
\hline Bacteroidetes & Flavobacteriales & Cryomorphaceae & Fluviicola & 5 \\
\hline Bacteroidetes & Sphingobacteriales & Chitinophagaceae & Sediminibacterium & 2 \\
\hline Bacteroidetes & Sphingobacteriales & $\mathrm{NS} 11-12^{a}$ & $\mathrm{NS} 11-12^{a}$ & 3 \\
\hline Cyanobacteria & Subsection I & Family I & Synechococcus & 3 \\
\hline Marinimicrobia & SAR406 clade & SAR406 clade & SAR406 clade & 4 \\
\hline Alphaproteobacteria & Caulobacterales & Caulobacteraceae & Brevundimonas & 4 \\
\hline Alphaproteobacteria & Rhizobiales & Methylobacteriaceae & Methylobacterium & 3 \\
\hline Alphaproteobacteria & Sphingomonadales & Sphingomonadaceae & Novosphingobium & 2 \\
\hline Alphaproteobacteria & Sphingomonadales & Sphingomonadaceae & Sphingobium & 3 \\
\hline Alphaproteobacteria & Sphingomonadales & Sphingomonadaceae & Sphingomonas & 3 \\
\hline Betaproteobacteria & Burkholderiales & Burkholderiaceae & Ralstonia & 2 \\
\hline Betaproteobacteria & Burkholderiales & Comamonadaceae & Aquabacterium & 2 \\
\hline Deltaproteobacteria & SAR324 clade & SAR324 clade & SAR324 clade & 3 \\
\hline Gammaproteobacteria & Alteromonadales & Alteromonadaceae & Marinobacter & 2 \\
\hline Gammaproteobacteria & E01-9C-26a & E01-9C-26a & E01-9C-26a & 2 \\
\hline Gammaproteobacteria & Oceanospirillales & Oceanospirillaceae & Pseudohongiella & 4 \\
\hline Gammaproteobacteria & Oceanospirillales & OM182 clade & OM182 clade & 2 \\
\hline Gammaproteobacteria & Oceanospirillales & SAR86 clade & SAR86 clade & 2 \\
\hline Gammaproteobacteria & Pseudomonadales & Moraxellaceae & Acinetobacter & 5 \\
\hline Gammaproteobacteria & Pseudomonadales & Pseudomonadaceae & Pseudomonas & 3 \\
\hline Gammaproteobacteria & Vibrionales & Vibrionaceae & Vibrio & 2 \\
\hline Euryarchaeota & Thermoplasmatales & Marine group II & Marine group II & 2 \\
\hline Thaumarchaeota & Unknown order & Unknown family & "Ca. Nitrosopumilus" & 2 \\
\hline
\end{tabular}

${ }^{a}$ Marine group.

${ }^{b}$ Ca., Candidatus.

nutrient availability and temperature are secondary to salinity in driving overall community composition (Fig. S2b).

Phylogenetic distance between marine and freshwater taxa. We next asked whether particular phyla, orders, and families tended to include closely related marine and freshwater representatives more often than others, reflecting more recent habitat transitions in these groups. Using UniFrac distances between marine and freshwater taxa (MED nodes) as a metric, calculated either pairwise between samples or together with all samples pooled, we found distances generally fell between 0.75 and 0.90 for each phylum (Fig. S3A). For individual orders and families, marine-freshwater distances spanned a greater range (Fig. S3; Table S1). Together, these results indicate that closely related marine and freshwater taxa can be found in most phyla, but they are not distributed uniformly across orders and families within those phyla; rather, some orders and families tend to be enriched in instances of closely related marine and freshwater taxa and therefore in putative recent transitions. For example, gammaproteobacterial families Chromatiaceae and Vibrionaceae and actinobacterial families PeM15 and Mycobacteriaceae had the smallest unweighted UniFrac distances $(<0.55)$ between marine and freshwater taxa, suggesting that marine and freshwater lineages tend to be more closely related in these groups. In contrast, Hydrogenophilaceae (Betaproteobacteria) and KI89A (Gammaproteobacteria) each had UniFrac distances of 1.00 (Table S1), indicating that marine and freshwater lineages we detected within these families were completely distinct phylogenetically.

At the finest taxonomic level, MED nodes, we observed 171 total shared MED nodes, i.e., nodes detected in at least one marine sample and one freshwater sample (Table 1; Fig. S4). For some phyla, our observations of shared taxa have saturated, while we expect to detect new shared taxa in other phyla with greater sampling effort (Fig. 2; Fig. S5). Betaproteobacteria and Gammaproteobacteria showed the largest increases in 

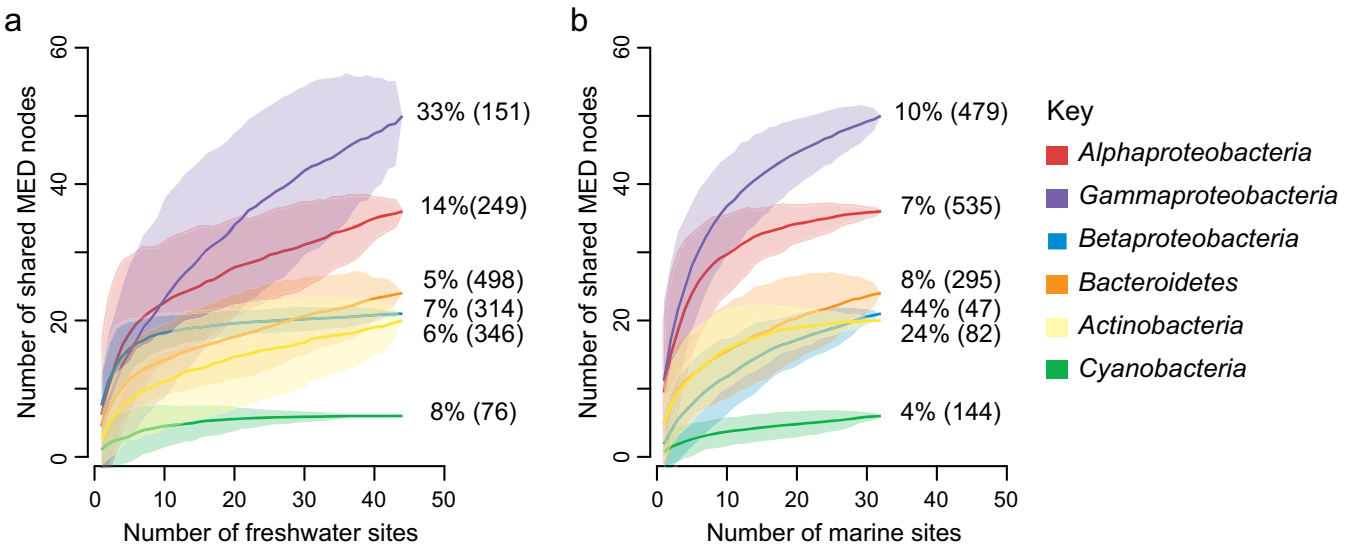

FIG 2 Species accumulation curves for taxonomic groups that contain shared marine and freshwater MED nodes as the number of freshwater sites included in the analysis increases (a) and as the number of marine sites included in the analysis increases (b). The percentage of sequences shared between habitats with all sites analyzed is included to the right of each curve; the total number of MED nodes within each group in freshwater and marine habitats, respectively, is indicated in parentheses.

the proportion of shared nodes as more marine and freshwater sites were sampled, respectively (Fig. S5). The pronounced increase in the proportion of betaproteobacterial shared nodes as more marine (but not freshwater) sites were analyzed indicates that nodes commonly observed in freshwater are sporadically detected in marine systems, and vice versa for Gammaproteobacteria. Gammaproteobacteria contained the most shared nodes, which accounted for $10 \%$ and $33 \%$ of total gammaproteobacterial nodes observed in marine and freshwater systems, respectively. Alphaproteobacteria contained the second highest number of shared nodes, accounting for $7 \%$ and $14 \%$ of total alphaproteobacterial nodes observed in marine and freshwater systems, respectively.

Direct sequence-level comparisons reveal variation across phyla. To quantify differences among phyla in their marine-freshwater transition history, we sought to compare all sequences in our data set using a fundamental metric-sequence identity-without assigning sequences to MED nodes or operational units. For each phylum, we constructed an all-versus-all distance matrix using pooled sequences from all samples, and clustered this matrix using every possible sequence identity threshold (to form $99.6 \%$ clusters, 99.3\%, 99.0\%, etc., given an amplicon size of $290 \mathrm{bp}$ ). Then, for all pairwise combinations of one marine and one freshwater sample (i.e., all marinefreshwater sample pairs), we identified the highest cluster threshold at which the two samples shared sequences in the same cluster (Fig. S6). We interpreted this threshold as a phylum-specific proxy for time since the most recent marine-freshwater transition: for example, finding $100 \%$ identical sequences in a marine and freshwater sample pair would imply a very recent transition event, whereas a cluster threshold of only $70 \%$ identity would imply a deep branching split into exclusively marine and freshwater clades (in other words, sequence clusters at all cutoffs greater than $70 \%$ would consist of exclusively marine or freshwater members). We summarized this identity threshold for each major phylum (class for Proteobacteria) and across all pairwise sample comparisons.

Using this approach, we found that most phyla contained shared taxa at identity thresholds $>99 \%$ for at least some pairs of marine and freshwater samples (Fig. 3). This result is not due to a few particular samples that tended to share taxa more frequently. Instead, it suggests that recent marine-freshwater transitions are phylogenetically and geographically widespread. At the same time, however, we also found substantial variation across phyla: some phyla showed widespread evidence for recent transitions across all sample pairs, while other phyla showed sporadic or no evidence for recent transitions (Fig. 3; Fig. S6 and S7). Within the Alpha- and Betaproteobacteria, for example, sequences typically were shared between marine and freshwater samples 


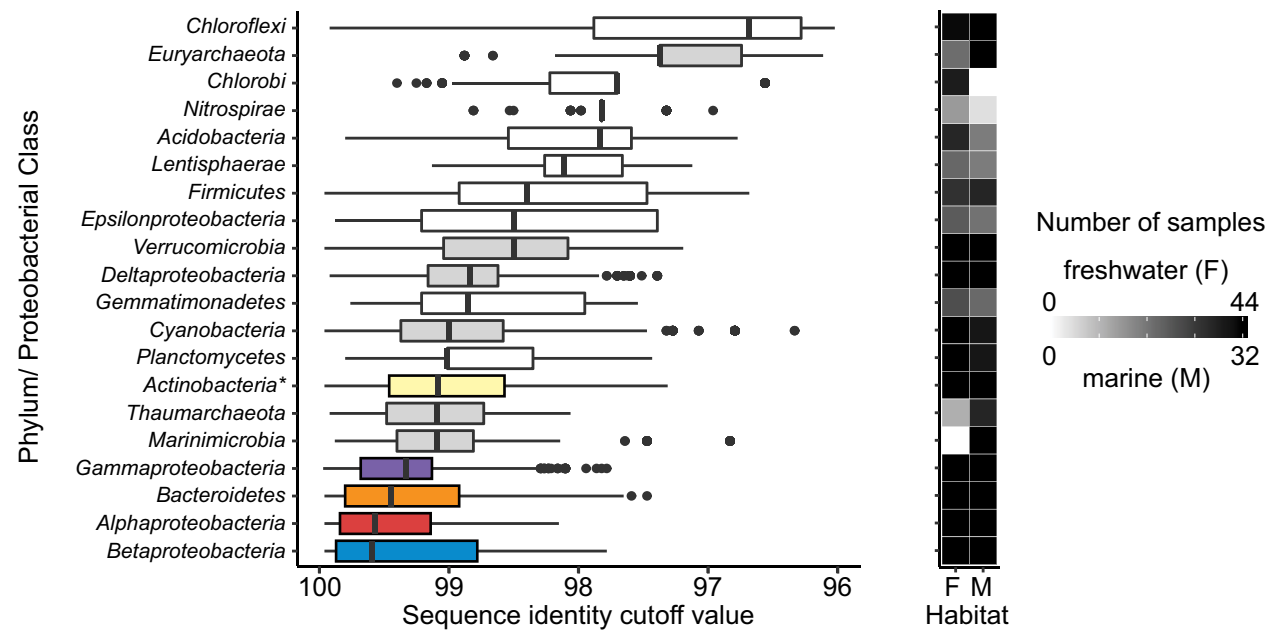

FIG 3 Maximum sequence identity threshold (i.e., finest-scale resolution) at which pairs of marine and freshwater samples share common taxa. Box plots indicate the median, quartiles, and range of values observed for all marine-freshwater sample pairs. Colored boxes indicate phyla/proteobacterial classes that contain 5 or more shared MED nodes while gray boxes indicate groups that contain 1 to 3 shared MED nodes. The heatmap to the right illustrates the number of freshwater (F) and marine (M) samples containing representatives of each phylum/proteobacterial class. *, Actinobacteria cutoff values were calculated with a preclustered data set (see Fig. S5 for comparison of all groups using a preclustered data set).

with $96 \%$ identity (median value for all pairwise sample comparisons). At the other extreme, no Nitrospirae sequences were found to be shared between marine and freshwater samples at $>89 \%$ identity. In addition, sequences from Chloroflexi, Euryarchaeota, and Chlorobi were rarely shared between marine and freshwater samples at $>77 \%$ identity.

Genome-wide evidence for recent marine-freshwater transitions in the SAR11 group. Given these overall phylogenetic patterns of marine-freshwater transitions, we sought to illustrate the implications for a single taxonomic group as a case study. We chose to focus on the SAR11 group of Alphaproteobacteria because representatives of this group are extremely abundant in both marine and freshwater systems, providing ample data in both habitat types. Further, this group has been the focus of a prior study which found that all freshwater SAR11 fell within the LD12 clade, reflecting a single major transition (14). Unexpectedly, our analysis detected several instances where non-LD12 SAR11 taxa (MED nodes) were found in freshwater: clades surface 1 and surface 2 were observed in a humic lake, an estuarine clade was observed in a Tibetan Plateau lake, and an unclassified SAR11 clade was observed in the Laurentian Great Lakes (Fig. 4a). Like many of the shared nodes in our data set, the marine (i.e., non-LD12) SAR11 shared nodes were detected at very low abundances in freshwater. One of the shared nodes was observed in the Laurentian Great Lakes, a system where we have been collecting microbial community data for several years, so we expanded our search for non-LD12 SAR11 to our larger data set, beyond the eleven samples initially included in the meta-analysis. Based on data sets acquired with the 515F/806R primer set, which is known to bias against the SAR11 clade (28), this non-LD12 SAR11 node accounted for 1 to 15 sequences out of an average of approximately 75,000 sequences per sample (Fig. 4b). The distribution of this node appears to be restricted to the hypolimnion during summer stratification; we detected it in surface samples only during spring sampling when the lakes were mixing.

We reasoned that if these typically marine SAR11 lineages were truly inhabiting the Great Lakes, we would expect to find genome-wide evidence beyond 16S rRNA. To test this, we extracted metagenome reads from the Great Lakes representing Pelagibacterales core genes and classified these reads into SAR11 clades using pplacer. We then quantified the relative abundance of classical freshwater LD12 and marine (non-LD12) clades based on this metagenome approach. For each metagenome analyzed, 59\% of 


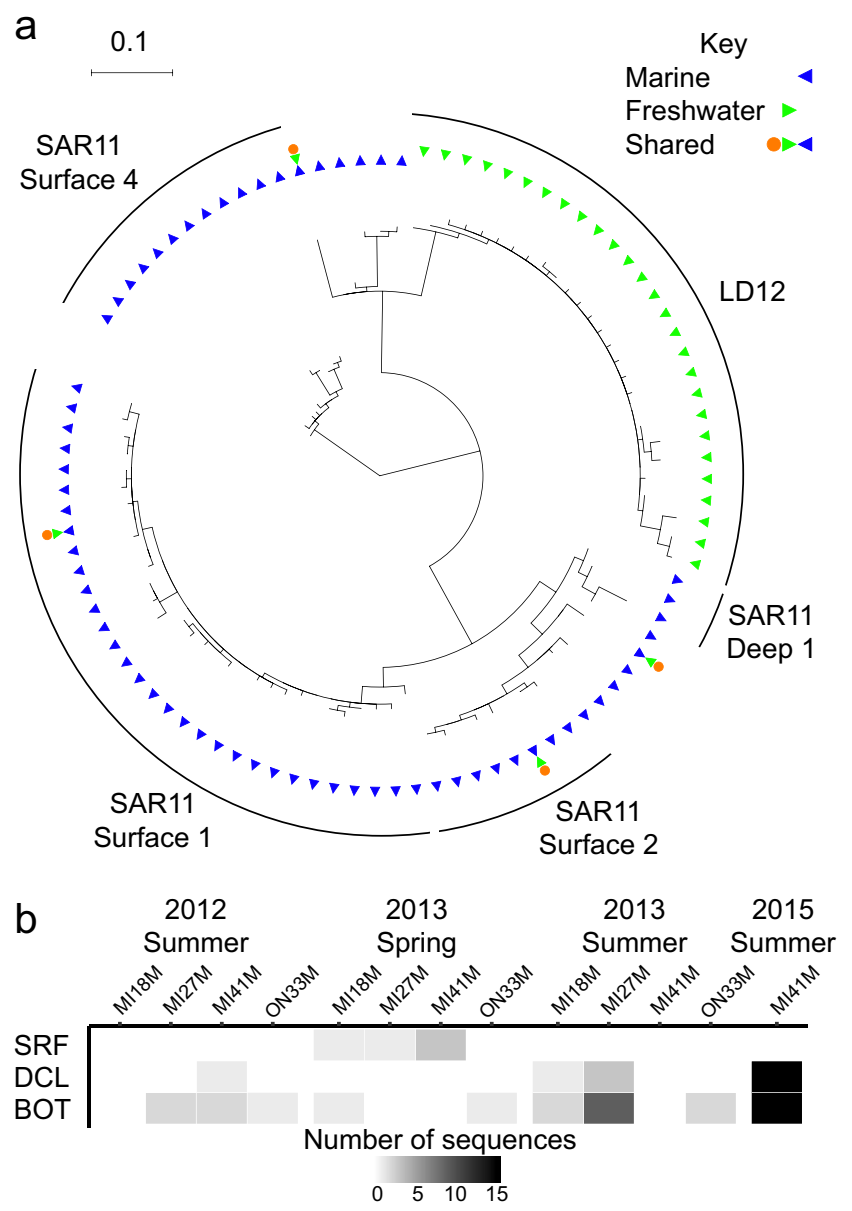

FIG 4 Observations of non-LD12 SAR11. (a) 16S rRNA V4 region gene tree constructed using representative sequences from each SAR11 node. The first ring indicates whether nodes were found only in marine (blue) or freshwater samples (green) while the second ring indicates nodes that are shared across habitat types (orange). (b) Number of non-LD12 SAR11 clade sequences detected at four stations (MI18M, MI27M, MI41M, ON33M) and three depths (SRF, surface; DCL, deep chlorophyll maximum layer; BOT, near-bottom) on Lakes Michigan and Ontario.

sequences within a typical (median) protein cluster could be classified as either LD12 or marine (non-LD12) SAR11 at a likelihood of 0.95 . Of the classified sequences, 11 to $12 \%$ (median value across all protein clusters) were classified as marine SAR11 in each of the Great Lakes samples; for comparison, $98 \%$ were classified as marine SAR11 in a marine sample from the Tara Oceans expedition (Fig. 5; Fig. S8). Across protein clusters, the fraction of sequences classified as marine (non-LD12) SAR11 was much more variable for Great Lakes samples (range 0 to 57\%, interquartile range 6 to 18\%) than for the marine sample (range 76 to $100 \%$, interquartile range 96 to 99\%). We identified 199 protein clusters with more than $5 \%$ of sequence reads classified as marine (non-LD12) SAR11 in all five Great Lakes metagenomes, suggesting that a substantial fraction of Great Lakes SAR11 cells resemble their marine cousins throughout their genomes, not just at the level of the $16 \mathrm{~S}$ rRNA gene.

\section{DISCUSSION}

Our meta-analysis sought to use newly available data sets, as well as new analyses, to revisit the paradigm of infrequent transitions between marine and freshwater habitats and identify lineages that may cross the salinity divide with higher or lower frequency than average. We found that marine and freshwater microbial communities were phylogenetically distinct at various phylogenetic resolutions, consistent with the conclusion of Lozupone and Knight (8) and Thompson and colleagues (9) that salinity 
a

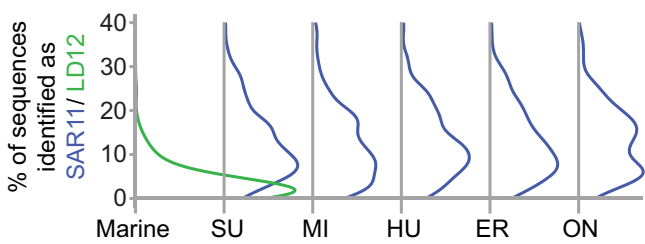

b

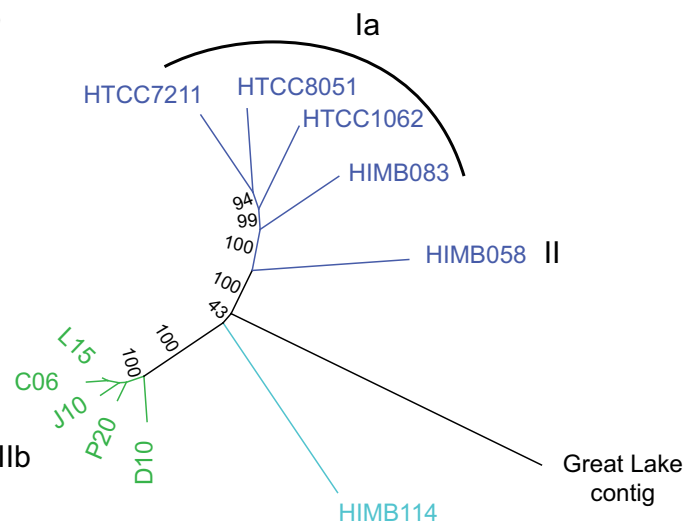

0.08

IIla

FIG 5 Metagenomic evidence for non-LD12 SAR11 in the Laurentian Great Lakes. (a) Percentage of classified reads identified as LD12 (green) in an open ocean sample (Marine), compared to marine (i.e., non-LD12) SAR11 (blue) in each of the five Laurentian Great Lakes (SU, Superior; MI, Michigan; HU, Huron; ER, Erie; ON, Ontario). Ridge plots present the distribution of identified reads across all protein clusters with greater than 100 reads classified as SAR11 or LD12 at a likelihood value of 0.95. (b) Neighbor-joining consensus tree of 1.2-kb nucleotide sequences from the protein cluster identified as COG2609 (pyruvate dehydrogenase complex, dehydrogenase E1 component). Strain names are colored based on phylogenetic classification within the SAR11 clade: green, LD12 sequences from group IIIb; light blue, group IIla, sister group to IIIb; medium blue, all other marine SAR11 clades included in the analysis (la, II); black, a contig assembled from the Lake Erie metagenome. Consensus support values (\%) are indicated on branches.

is the major environmental determinant separating free-living bacteria from different environments. Further, our finding of higher relative abundances of Betaproteobacteria and Actinobacteria in lakes and higher relative abundances of Alphaproteobacteria and Gammaproteobacteria in marine systems corresponds with taxonomic comparisons made using metagenomic sequence data sets (29) as well as previous observations using $16 \mathrm{~S}$ rRNA sequences $(16,30)$.

Taxonomic groups with comparatively high transition frequency. We used multiple approaches to compare relative marine-freshwater transition frequency across phylogenetic groups, based on two key assumptions: (i) the more similar two sequences are, the more recently a common ancestor transitioned between marine and freshwater habitat types, and (ii) each clade containing shared taxa, including every shared node, encompasses at least one transition between habitat types. From these analyses, a coherent picture has begun to emerge. Most phyla contain at least a few instances of recent transitions, but these recent transitions are not evenly distributed. Alphaproteobacteria, Betaproteobacteria, Bacteroidetes, Gammaproteobacteria and Actinobacteria were inferred to have the most frequent transitions between marine and freshwater systems based on the number of shared MED nodes, i.e., taxa detected in both marine and freshwater systems. Using our direct sequence comparison method, these phyla also exhibited high (>90\%) average identity between nearest marine and freshwater representatives (Fig. 3). These phyla encompass a variety of aquatic lifestyles, from small streamlined SAR11 cells that harvest low-molecular-weight dissolved organic matter (31) to particle-attached Bacteroidetes with the ability to degrade polymers and genes for gliding motility (32). More frequent transitions in these phyla 
may stem, in part, from their abundance: Alphaproteobacteria and Gammaproteobacteria are two of the most abundant phyla in marine systems while Actinobacteria, Betaproteobacteria and Bacteroidetes dominate freshwater lakes, increasing the probability of dispersal across habitat types.

In addition, particular lineages within these phyla may have evolved traits that facilitate successful colonization across a range of environments and salinities (e.g., through lateral gene transfer [33]). These phyla all include organisms capable of photoheterotrophy, which may enable microbial cells to persist until conditions arise that allow population expansion (3, 34-38). A number of aquatic bacterial strains have also been identified as salinity generalists, including representatives of the Comamonadaceae (Betaproteobacteria), Pseudomonadaceae (Gammaproteobacteria), Vibrionaceae (Gammaproteobacteria), and Pseudoalteromonadaceae (Gammaproteobacteria) (39); all four of these families contained shared MED nodes in our meta-analysis (13, 4, 5 , and 1 node[s], respectively). Notably, Actinobacteria had lower sequence similarity between pairs of marine and freshwater samples and contained fewer shared nodes than the other four major groups. Below-average growth rates (40) and the dependence of some actinobacterial lineages on other bacteria (41) may contribute to apparent differences in the ability of Actinobacteria and other abundant taxa to transition between marine and freshwater systems.

Insights from the SAR11 group. Initial evidence pointed to a single marinefreshwater transition in the evolutionary diversification of SAR11, based on the observation that all SAR11 detected in freshwater systems belonged to the LD12 clade while no marine sequences were identified as LD12 (14). Recent findings, including our work, have begun to blur this picture. The first indication that non-LD12, marine-like SAR11 inhabit lakes came from a recently reconstructed partial genome classified as SAR11 subtype I/II from Lake Baikal (42). Here, we detected distinct marine (non-LD12) lineages of SAR11 in each of three lake systems: a humic lake in northern Wisconsin, a Tibetan Plateau lake, and the Laurentian Great Lakes. The same non-LD12 SAR11 node was detected in Lakes Michigan and Ontario across multiple years, depths, and stations within each lake, suggesting an established population in this system. Using phylogenetic placement of metagenome reads, we found further evidence for non-LD12 SAR11 in the Great Lakes. Most metagenome reads could not be unambiguously classified to a particular clade, which could indicate that we lack a closely related genome representative. The reads that were classified fell into clades la and IIIa, a sister group of LD12 (also known as clade IIIb) commonly found in brackish environments $(10,43,44)$; they were not classified with the partial genome from Lake Baikal, implying distinct nonLD12 lineages in these two large-lake ecosystems. Together these findings provide robust evidence that non-LD12 SAR11 inhabit freshwater habitats.

As ecological data accumulate, the challenge becomes reconciling the distributions of specific lineages with their evolutionary history. Comparative genomics suggests that the LD12 lineage descended from a marine ancestor that lost particular genes related to osmolyte uptake, consistent with the ecological distribution of LD12 cells in freshwater and low-salinity brackish environments but not in higher-salinity marine environments $(45,46)$. Members of the LD12 clade are also distinguished from their marine cousins by carbon metabolism pathways $(47,48)$, though how these changes are related to freshwater adaptation remains unclear. Our observations of additional SAR11 lineages in inland lakes (i.e., non-LD12), as well as the recovery of a non-LD12 partial genome from Lake Baikal, raise a number of questions. Do these SAR11 lineages also possess specific genome adaptations to freshwater, and are these adaptations the same as or similar to those acquired by LD12? Such adaptations might include gene gains and losses $(33,46,48)$, and also a freshwater-like distribution of protein isoelectric points (i.e., fewer acidic proteins, more basic proteins) as observed in the Lake Baikal partial genome $(42,49)$. Furthermore, are the global dominance of LD12 and the relative obscurity of other SAR11 lineages in freshwater due to specific genome features or chance (e.g., LD12 arrived first and filled available niche space)? Is there 
potential for future freshwater population expansions for these lineages? Insight into these questions may come from whole-genome sequences from these new freshwater lineages, as well as physiological studies of cultured isolates.

Detection limits and overlooked diversity. Organisms with abundances at or near the detection limits of current sequencing practices are frequently removed from analyses that exclude sequences below a specified abundance threshold (27). However, populations with low representation in sequencing libraries may have unintuitively large census population sizes in a system. A population with a density of one cell per $\mathrm{ml}$ has a population size of billions of cells in a one-meter-depth layer of a small lake like Trout Bog and quadrillions of cells in a one-meter-depth layer of Lake Michigan. Assuming that the probability of sequencing is proportional to cell abundance and there are 500,000 cells per $\mathrm{ml}$, a sequence from that population will not be detected $74 \%$ of the time and a single sequence will be detected $22 \%$ of the time from a sample with 150,000 sequences (slightly higher than any samples included in our metaanalysis), making the population likely to go unreported. Aquatic systems contain a systematically overlooked pool of diversity that may harbor organisms that immigrated from other habitats but have not become dominant in the system. These frequently overlooked low-abundance taxa may make disproportionately large contributions to ecosystem function (50) and could serve as a source of taxa available to take advantage of changing environmental conditions, akin to what Shade and colleagues (51) describe as "conditionally rare taxa."

Using 16S rRNA data sets to detect transitions. There are several important caveats to consider when comparing microbial diversity between habitat types. First, we can only survey abundant, extant diversity. Analyzing $16 \mathrm{~S}$ rRNA amplicon data sets gave us the benefit of deep sequencing relative to other approaches, but the 16S rRNA gene is not a good marker for differentiating closely related organisms (52). Marine and freshwater microorganisms classified as "shared" in our analyses may in fact exhibit substantial habitat-specific genome differentiation, and may be distinguishable as fine-scale sequence clusters based on the full-length 16S rRNA sequence or another housekeeping gene. Microbial community composition can also be affected by biases, including those resulting from DNA extraction method (53) and 16S rRNA gene primer set $(28,54)$. Shared taxa could potentially arise due to reagent contamination (55) or sample cross-contamination (56), but these issues are unlikely to explain our metaanalysis results, given that samples were processed and sequenced independently for each study.

Summary. Marine and freshwater systems are phylogenetically distinct, while at the same time harboring taxa that appear in both environments. Some taxonomic groups appear to be exclusive to marine or freshwater environments. At the same time, some taxonomic units appear in both habitat types; we identified 171 shared MED nodes across marine and freshwater habitats. It remains to be seen whether individual cells with marine-like or freshwater-like 16S rRNA resemble populations found in the other habitat genome-wide, or whether there is genomic mosaicism. Families at the extremes-lineages with a high degree of habitat-specific diversification or a large number of taxa found in both habitats-may serve as targets for future work investigating ecological plasticity and/or adaptations and the evolution of microbial lineages. There is clearly precedent and potential for marine and freshwater organisms to transition between habitats with different salinities and adapt to new environmental conditions, available resources, and interactions with neighboring organisms. A bank of near- or below-detection diversity, including cross-system immigrant populations, may contribute to community genomic diversity via horizontal gene transfer and exploit opportunities for niche expansion as environmental conditions change.

\section{MATERIALS AND METHODS}

$16 \mathrm{~S}$ rRNA sequence processing. We carried out a meta-analysis of marine and freshwater $16 \mathrm{~S}$ rRNA gene sequencing data sets spanning the V4 region (Table 2; see also Table S2 in the supplemental material). For a data set to be included in our analysis, sequence reads needed to encompass bases 515 through 805 of the $16 \mathrm{~S}$ rRNA gene. We augmented publicly available data sets with samples from the 
TABLE 2 16S rRNA v4 region sequencing data sets included in the meta-analysis

\begin{tabular}{|c|c|c|c|}
\hline No. of samples & Study system & Depth(s) sampled ${ }^{a}$ & $\begin{array}{l}\text { BioProject accession no. } \\
\text { (reference) }\end{array}$ \\
\hline \multicolumn{4}{|c|}{ Freshwater samples (45 total) } \\
\hline 11 & Four Laurentian Great Lakes & Surface, DCL, deep & This study \\
\hline 1 & JBL_J07_HES, Sweden & Integrated & PRJNA244610 (79) \\
\hline 1 & Lake Keluke, China & Surface & PRJNA294836 (80) \\
\hline 1 & Faselfad lakes, Austria & Integrated & PRJNA297573 (81) \\
\hline 6 & Three humic lakes, WI & Integrated epi, integrated hypo & PRJEB15148 (83) \\
\hline \multicolumn{4}{|c|}{ Marine samples (32 total) } \\
\hline 1 & Caribbean Sea & Surface & PRJEB10633 (28) \\
\hline 2 & Coastal Red Sea (2 sites) & Surface & PRJNA279146 (54) \\
\hline 1 & Drake Passage & Surface & PRJEB10633 (28) \\
\hline 12 & Gulf of Mexico (3 sites) & Surface, multiple depths & PRJNA327040 (84) \\
\hline 2 & Sargasso Sea (2 sites) & Surface, $200 \mathrm{~m}$ & PRJEB10633 (28) \\
\hline 1 & Tropical Western Atlantic Ocean & $40 \mathrm{~m}$ & PRJEB10633 (28) \\
\hline 1 & Weddell Sea & Surface & PRJEB10633 (28) \\
\hline
\end{tabular}

${ }^{a}$ Abbreviations: DCL, deep chlorophyll layer; epi, epilimnion; hypo, hypolimnion.

Laurentian Great Lakes sequenced by the Joint Genome Institute. Sequence processing was carried out using mothur v 1.38.1 unless otherwise noted (57). We merged paired sequence reads using make.contigs and quality filtered single reads using trim.seqs (window size $=50$, minimum average quality score $=35$ ). All sequences were then combined and processed following a modified version of the mothur MiSeq standard operating protocol accessed 27 September 2016 (58). Screening retained 200- to 300-bp sequences with no ambiguities and maximum homopolymer stretches fewer than 24 bases. Screened sequences were aligned to the Silva v128 reference alignment $(59,60)$, and chimeras were identified using UCHIME (61) and removed. Sequences were classified in mothur using Silva v128, and those identified as "Chloroplast," "Mitochondria," "unknown," or "Eukaryota" were removed from the data set.

We used two approaches to cluster similar sequences. First, we implemented minimum entropy decomposition (MED), a method that employs Shannon entropy to partition sequences into taxonomic units referred to as "nodes" using information-rich nucleotide positions and ignoring stochastic variation (27). We ran MED with a minimum substantive abundance of 10 sequences and 4 discriminant locations. Second, to quantify taxon relatedness based on absolute sequence identity, we implemented direct comparisons for all sequences within each phylum (proteobacterial class). We calculated pairwise sequence distances and used farthest-neighbor clustering to cluster sequences at all possible sequence identity cutoff values, from $100 \%$ identity down to the level where all sequences collapse into a single cluster, at a precision of 1,000. For groups with distance matrices too large to process all sequences together (Alphaproteobacteria, Bacteroidetes, Betaproteobacteria, Gammaproteobacteria), cluster.split was implemented at the order level (taxonomic level 4) to group sequences into taxonomic units at cutoff values from unique down to 0.30. Classification-based cluster splitting was not a feasible approach for Actinobacteria, so pre.cluster was run on sequences prior to calculating furthest-neighbor clusters.

Statistical and phylogenetic comparisons of marine and freshwater data sets. We compared marine and freshwater samples and sequences at the levels of taxonomic classification, MED nodes, and sequence identity using $R$ version 3.3.2 (R Core Team, 2016). Phyla (proteobacterial classes) that were differentially abundant in marine versus freshwater samples were identified by testing for differences in the $\log _{2}$ fold change using a parametric Wald test implemented by DESeq2 (62).

To quantify phylogenetic distance between marine and freshwater taxa, we first generated a maximum-likelihood tree from mothur-aligned sequences using the GTRGAMMA model in RaxML v7.7.9 (63). To visualize subtrees and calculate UniFrac distances for specific groups, bacterial trees were rooted with a Marine Group I archaeal sequence (A000001667) using the APE R package (64). Trees were visualized using the interactive Tree Of Life (65). Sequences were rarefied, and data were subset for subsequent analyses using the phyloseq package (66). We rarefied samples to even depth $(9,827$ sequences/sample) and calculated unweighted UniFrac distances for each pair of samples using GUniFrac (67). We tested the significance of UniFrac distances between marine and freshwater samples using permutational multivariate analysis of variance (PerMANOVA) as implemented by the Adonis function in the Vegan package (68). The same approach was used to calculate UniFrac values for each phylum and proteobacterial class that was observed in at least three marine and three freshwater samples and contained at least five MED nodes. Samples containing fewer than 500 sequences for a given phylum or class were removed from the analysis. We combined all sequences from each habitat and calculated 
TABLE 3 SAR11 and LD12 genomes included in pangenomic analysis

\begin{tabular}{|c|c|c|c|}
\hline Genome name & SAR11 clade & Classification & GenBank accession no. \\
\hline Alphaproteobacterium HIMB114 & Illa & SAR11 & NZ_ADAC02000001 \\
\hline "Candidatus Pelagibacter" sp. HTCC7211 & la.2 & SAR11 & ABVS00000000 \\
\hline "Candidatus Pelagibacter ubique" HIMB058 & II & SAR11 & ATTF01000000 \\
\hline "Candidatus Pelagibacter ubique" HIMB083 & la.2 & SAR11 & AZAL00000000 \\
\hline "Candidatus Pelagibacter ubique" HTCC1062 & la.1 & SAR11 & NC_007205 \\
\hline SCGC AAA027-C06 & Illlb & LD12 & AQPD00000000 \\
\hline SCGC AAA028-C07 & Illlb & LD12 & АТТВ01000000 \\
\hline SCGC AAA028-D10 & Illb & LD12 & AZOF00000000 \\
\hline SCGC AAA280-P20 & Illlb & LD12 & AQUE00000000 \\
\hline SCGC AAA023-L09 & Illlb & LD12 & ATTD01000000 \\
\hline SCGC AAA027-L15 & IIllb & LD12 & AQUG00000000 \\
\hline SCGC AAA487-M09 & Illb & LD12 & АТTC00000000 \\
\hline
\end{tabular}

unweighted UniFrac distances for phyla, proteobacterial classes, orders and families using GUniFrac following sequence rarefaction to even depth. To test the significance of calculated UniFrac values for each phylum and proteobacterial class, unweighted UniFrac values were calculated for 1,000 independent swap randomizations of the presence-absence sample matrix generated by the randomizeMatrix function in the Picante package (69). Using these distances as a null distribution, one-sample $z$ tests were conducted to test the null hypothesis that the phylogenetic tree is not grouped by habitat. A Bonferroni correction was implemented as a conservative measure to account for multiple testing in determining significance.

We identified "shared nodes" as MED nodes observed in the unrarefied sequence set for at least one marine and at least one freshwater sample. For each phylum (proteobacterial class) containing more than five nodes observed in both marine and freshwater samples (i.e., shared nodes), we generated accumulation curves to visualize the number of shared MED nodes as a function of the number of freshwater or marine sampling sites using the specaccum function in the vegan package (68).

To compare sequence clusters generated at each sequence identity cutoff, we calculated Jaccard distances for pairs of unrarefied samples (one marine and one freshwater) for each phylum (proteobacterial class). The Jaccard distance is calculated as 1 minus the intersection of two samples (i.e., the number of shared units) divided by the union of two samples (i.e., the total number of units); a Jaccard distance of 1 means that no taxa are shared between samples. The sequence identity cutoff value at which marine-freshwater sample pairs first contain shared taxa (Jaccard distance $<1$ ) was summarized for each phylum/class using boxplots.

Metagenomic evidence of non-LD12 SAR11 in the Great Lakes. To test whether there is genome-wide evidence beyond the 16S rRNA locus for non-LD12 SAR11 cells in the Great Lakes, we identified reads that mapped with high confidence to non-LD12 SAR11 in a SAR11/LD12 reference phylogeny. Briefly, we analyzed merged pairs of metagenome sequencing reads from samples collected from the surface of each of the Great Lakes in spring 2012 (IMG taxon object IDs: 3300005580 , $3300005582,3300005583,3300005584,3300005585)$ as well as a marine sample from the Tara Oceans project collected from the North Atlantic Ocean Westerlies Biome near Bermuda for comparison (accession number ERR599123) (70). Sequence reads from each metagenome were searched against the nr protein database (71; downloaded 13 April 2017) using Diamond v. 0.8.18.80 (72), and sequences whose best hit matched the Pelagibacterales family were identified using Krona Tools v. 2.7 (73) and extracted. These putative Pelagibacterales reads were then mapped to a database of SAR11/LD12 protein clusters using a translated query-protein subject (blastx) BLAST v. 2.2.28 (74) with E value $<0.001$ and alignment length $>60$ amino acids ( $>50$ amino acids for the Tara Oceans sample since sequence reads were shorter). We set a liberal $E$ value threshold for this reciprocal BLAST step in order to sensitively map short metagenomic fragments to protein clusters; in practice, the median E value for mapping reads in this step was $2 \times 10^{-47}$, with $99 \%$ of query reads yielding $E$ values less than $2 \times 10^{-15}$ and $99.7 \%$ of reads yielding E values less than $1 \times 10^{-6}$. Our protein cluster database was constructed from publicly available SAR11 and LD12 genomes (Table 3) using all-vs-all blastp and MCL clustering (75) as implemented by Anvi'o v. 2.4 .0 (76). We focused our analysis on putative core protein clusters found in single copy in at least 6 SAR11 genomes and 3 LD12 genomes; notably, all but one LD12 genome derive from single-cell genome amplification and sequencing and are therefore incomplete. For each protein cluster, we backtranslated amino acid alignments, generated by MUSCLE v. 3.8 (77) within Anvi'o, to nucleotide alignments. We then used RAxML v. 7.2.6 with the GTRGAMMA model to generate a maximum likelihood tree for each protein cluster based on its corresponding nucleotide alignment (63). Metagenomic reads that mapped to each protein cluster by blastx were aligned to the cluster's reference nucleotide 
alignment using HMMER $v 3.1 \mathrm{~b} 2$ ( $\mathrm{hmmer} .0 \mathrm{~g}$ ). Reads were then classified taxonomically using pplacer with the $-p$ flag to calculate prior probabilities and guppy classify using the -pp flag to use posterior probability for the pplacer classifier criteria v1.1.alpha19-0-g807f6f3 (78). The reference package for taxonomy classification was generated using taxtastic v 0.5 .4 (http://fhcrc.github.io/taxtastic/index.html). We analyzed the resulting databases using the R package BoSSA v2.1 (https://cran.r-project.org/web/ packages/BoSSA/index.html).

Data availability. Laurentian Great Lakes sequences are available on the Joint Genome Institute's genome data portal (http://genome.jgi.doe.gov/; project identifiers, 1045074 and 1045077). R code and associated data files are available at https://bitbucket.org/greatlakes/marine_fw_meta.git. Intermediate data files referenced in code but too large to store on bitbucket are available on figshare at https://doi .org/10.6084/m9.figshare.7180649.v1.

\section{SUPPLEMENTAL MATERIAL}

Supplemental material for this article may be found at https://doi.org/10.1128/ mSystems.00232-18.

FIG S1, EPS file, $0.5 \mathrm{MB}$.

FIG S2, EPS file, $0.5 \mathrm{MB}$.

FIG S3, EPS file, $0.3 \mathrm{MB}$.

FIG S4, EPS file, $1.6 \mathrm{MB}$.

FIG S5, EPS file, $0.4 \mathrm{MB}$.

FIG S6, EPS file, $0.9 \mathrm{MB}$.

FIG S7, EPS file, $0.4 \mathrm{MB}$.

FIG S8, JPG file, $0.8 \mathrm{MB}$.

TABLE S1, PDF file, $0.04 \mathrm{MB}$.

TABLE S2, PDF file, 0.1 MB.

\section{ACKNOWLEDGMENTS}

This work was supported by the University of Chicago Women's Board and IllinoisIndiana Sea Grant, grant number NA14OAR170095.

Great Lakes samples were sequenced by the DOE Joint Genome Institute (CSP no. 1565), and computational resources were provided by the University of Chicago Research Computing Center. We thank Glenn Warren and the science staff in the Great Lakes National Program Office of the US EPA and the captain and crew of the R/V Lake Guardian for facilitating sample collection on the Great Lakes, A. M. Eren for assistance with MED, J. Podowski for help with analysis, and Jacob Waldbauer, the Coleman and Waldbauer lab groups at UChicago, and two anonymous reviewers for constructive feedback.

Author contributions were as follows: study conception and design, S.F.P. and M.L.C.; analysis and interpretation of data, S.F.P., D.M., R.J.N., and M.L.C.; drafting of manuscript, S.F.P. and M.L.C.; critical revision, S.F.P., D.M., R.J.N., and M.L.C.

\section{REFERENCES}

1. Grossart H-P. 2010. Ecological consequences of bacterioplankton lifestyles: changes in concepts are needed. Environ Microbiol Rep 2:706-714. https://doi.org/10.1111/j.1758-2229.2010.00179.x.

2. Cole JJ. 1982. Interactions between bacteria and algae in aquatic ecosystems. Annu Rev Ecol Syst 13:291-314. https://doi.org/10.1146/ annurev.es.13.110182.001451.

3. Kobližek M. 2015. Ecology of aerobic anoxygenic phototrophs in aquatic environments. FEMS Microbiol Rev 39:854-870. https://doi.org/10.1093/ femsre/fuv032.

4. Mizuno CM, Rodriguez-Valera F, Ghai R. 2015. Genomes of planktonic Acidimicrobiales: widening horizons for marine actinobacteria by metagenomics. mBio 6:e02083-14. https://doi.org/10.1128/mBio.02083-14.

5. Salcher MM, Neuenschwander SM, Posch T, Pernthaler J. 2015. The ecology of pelagic freshwater methylotrophs assessed by a highresolution monitoring and isolation campaign. ISME J 9:2442-2453. https://doi.org/10.1038/ismej.2015.55.

6. Martiny JBH, Jones SE, Lennon JT, Martiny AC. 2015. Microbiomes in light of traits: a phylogenetic perspective. Science 350:aac9323. https://doi .org/10.1126/science.aac9323.

7. Dupont $\mathrm{CL}$, Larsson J, Yooseph S, Ininbergs K, Goll J, Asplund-
Samuelsson J, McCrow JP, Celepli N, Allen LZ, Ekman M, Lucas AJ, Hagström Å, Thiagarajan M, Brindefalk B, Richter AR, Andersson AF, Tenney A, Lundin D, Tovchigrechko A, Nylander JAA, Brami D, Badger JH, Allen AE, Rusch DB, Hoffman J, Norrby E, Friedman R, Pinhassi J, Venter JC, Bergman B. 2014. Functional tradeoffs underpin salinity-driven divergence in microbial community composition. PLoS One 9:e89549. https://doi.org/10.1371/journal.pone.0089549.

8. Lozupone CA, Knight R. 2007. Global patterns in bacterial diversity. Proc Natl Acad Sci U S A 104:11436-11440. https://doi.org/10.1073/pnas .0611525104 .

9. Thompson LR, Sanders JG, McDonald D, Amir A, Ladau J, Locey KJ, Prill RJ, Tripathi A, Gibbons SM, Ackermann G, Navas-Molina JA, Janssen S, Kopylova E, Vázquez-Baeza Y, Gonzalez A, Morton JT, Mirarab S, Zech Xu Z, Jiang L, Haroon MF, Kanbar J, Zhu Q, Jin Song S, Kosciolek T, Bokulich NA, Lefler J, Brislawn CJ, Humphrey G, Owens SM, Hampton-Marcell J, Berg-Lyons D, McKenzie V, Fierer N, Fuhrman JA, Clauset A, Stevens RL, Shade A, Pollard KS, Goodwin KD, Jansson JK, Gilbert JA, Knight R, Earth Microbiome Project Consortium. 2017. A communal catalogue reveals Earth's multiscale microbial diversity. Nature 551:457-463. https://doi .org/10.1038/nature24621. 
10. Herlemann DP, Labrenz M, Jürgens K, Bertilsson S, Waniek JJ, Andersson AF. 2011. Transitions in bacterial communities along the $2000 \mathrm{~km}$ salinity gradient of the Baltic Sea. ISME J 5:1571-1579. https://doi.org/10.1038/ ismej.2011.41.

11. Fortunato CS, Crump BC. 2015. Microbial gene abundance and expression patterns across a river to ocean salinity gradient. PLoS One 10: e0140578. https://doi.org/10.1371/journal.pone.0140578.

12. Logares R, Lindström ES, Langenheder S, Logue JB, Paterson $H$, Laybourn-Parry J, Rengefors K, Tranvik L, Bertilsson S. 2013. Biogeography of bacterial communities exposed to progressive long-term environmental change. ISME J 7:937-948. https://doi.org/10.1038/ismej.2012 .168 .

13. Logares R, Bråte J, Bertilsson S, Clasen JL, Shalchian-Tabrizi K, Rengefors K. 2009. Infrequent marine-freshwater transitions in the microbial world. Trends Microbiol 17:414-422. https://doi.org/10.1016/j.tim.2009.05.010.

14. Logares R, Bråte J, Heinrich F, Shalchian-Tabrizi K, Bertilsson S. 2010. Infrequent transitions between saline and fresh waters in one of the most abundant microbial lineages (SAR11). Mol Biol Evol 27:347-357. https://doi.org/10.1093/molbev/msp239.

15. Zwart G, Crump BC, Kamst-van Agterveld MP, Hagen F, Han SK. 2002. Typical freshwater bacteria: an analysis of available 16S rRNA gene sequences from plankton of lakes and rivers. Aquat Microb Ecol 28: 141-155. https://doi.org/10.3354/ame028141.

16. Newton RJ, Jones SE, Eiler A, McMahon KD, Bertilsson S. 2011. A guide to the natural history of freshwater lake bacteria. Microbiol Mol Biol Rev 75:14-49. https://doi.org/10.1128/MMBR.00028-10.

17. Hubbell SP. 2001. The unified neutral theory of biodiversity and biogeography. Princeton University Press, Princeton, NJ.

18. Lenski RE, Rose MR, Simpson SC, Tadler SC. 1991. Long-term experimental evolution in Escherichia coli. I. Adaptation and divergence during 2,000 generations. Am Nat 138:1315-1341. https://doi.org/10.1086/ 285289.

19. Elena SF, Lenski RE. 2003. Microbial genetics: evolution experiments with microorganisms: the dynamics and genetic bases of adaptation. Nat Rev Genet 4:457-469. https://doi.org/10.1038/nrg1088.

20. Bootsma HA. 2018. Oceans, lakes, and inland seas: a virtual issue on the large lakes of the world. Limnol Oceanogr Bull 27:87-88. https://doi .org/10.1002/lob.10230.

21. Janssen J, Marsden JE, Hrabik TR, Stockwell JD. 2014. Are the Laurentian Great Lakes great enough for Hjort? ICES J Mar Sci 71:2242-2251. https://doi.org/10.1093/icesjms/fst220.

22. Hecky RE, Campbell P, Hendzel LL. 1993. The stoichiometry of carbon, nitrogen, and phosphorus in particulate matter of lakes and oceans. Limnol Oceanogr 38:709-724. https://doi.org/10.4319/lo.1993.38.4.0709.

23. Paytan A, McLaughlin K. 2007. The oceanic phosphorus cycle. Chem Rev 107:563-576. https://doi.org/10.1021/cr0503613.

24. Sterner RW. 2010. In situ-measured primary production in Lake Superior. J Great Lakes Res 36:139-149. https://doi.org/10.1016/j.jglr.2009.12.007.

25. Guildford SJ, Hecky RE. 2000. Total nitrogen, total phosphorus, and nutrient limitation in lakes and oceans: is there a common relationship? Limnol Oceanogr 45:1213-1223. https://doi.org/10.4319/lo.2000.45.6 .1213.

26. Paver S, Muratore DJ, Newton RJ, Coleman M. 2018. Re-evaluating the salty divide: phylogenetic specificity of transitions between marine and freshwater systems. bioRxiv https://doi.org/10.1101/347021.

27. Eren AM, Morrison HG, Lescault PJ, Reveillaud J, Vineis JH, Sogin ML. 2015. Minimum entropy decomposition: unsupervised oligotyping for sensitive partitioning of high-throughput marker gene sequences. ISME J 9:968-979. https://doi.org/10.1038/ismej.2014.195.

28. Parada AE, Needham DM, Fuhrman JA. 2016. Every base matters: assessing small subunit rRNA primers for marine microbiomes with mock communities, time series and global field samples. Environ Microbiol 18:1403-1414. https://doi.org/10.1111/1462-2920.13023.

29. Eiler A, Zaremba-Niedzwiedzka K, Martínez-García M, McMahon KD, Stepanauskas R, Andersson SGE, Bertilsson S. 2014. Productivity and salinity structuring of the microplankton revealed by comparative freshwater metagenomics. Environ Microbiol 16:2682-2698. https://doi.org/ 10.1111/1462-2920.12301.

30. Barberán A, Casamayor EO. 2010. Global phylogenetic community structure and $\beta$-diversity patterns in surface bacterioplankton metacommunities. Aquat Microb Ecol 59:1-10. https://doi.org/10.3354/ame01389.

31. Giovannoni SJ. 2017. SAR11 bacteria: the most abundant plankton in the oceans. Annu Rev Mar Sci 9:231-255. https://doi.org/10.1146/annurev -marine-010814-015934.
32. Fernández-Gómez B, Richter $M$, Schüler M, Pinhassi J, Acinas SG, González JM, Pedrós-Alió C. 2013. Ecology of marine Bacteroidetes: a comparative genomics approach. ISME J 7:1026-1037. https://doi.org/ 10.1038/ismej.2012.169.

33. Walsh DA, Lafontaine J, Grossart H-P. 2013. On the eco-evolutionary relationships of fresh and salt water bacteria and the role of gene transfer in their adaptation, p 55-77. In Gophna U (ed), Lateral gene transfer in evolution. Springer, New York, NY.

34. Gómez-Consarnau L, Akram N, Lindell K, Pedersen A, Neutze R, Milton DL, González JM, Pinhassi J. 2010. Proteorhodopsin phototrophy promotes survival of marine bacteria during starvation. PLoS Biol 8:e1000358. https://doi.org/10.1371/journal.pbio.1000358.

35. Brindefalk B, Ekman M, Ininbergs K, Dupont CL, Yooseph S, Pinhassi J, Bergman B. 2016. Distribution and expression of microbial rhodopsins in the Baltic Sea and adjacent waters. Environ Microbiol 18:4442-4455. https://doi.org/10.1111/1462-2920.13407.

36. Martínez-García M, Swan BK, Poulton NJ, Gomez ML, Masland D, Sieracki ME, Stepanauskas R. 2012. High-throughput single-cell sequencing identifies photoheterotrophs and chemoautotrophs in freshwater bacterioplankton. ISME J 6:113-123. https://doi.org/10.1038/ismej.2011.84.

37. Béjà O, Suzuki MT, Heidelberg JF, Nelson WC, Preston CM, Hamada T, Eisen JA, Fraser CM, DeLong EF. 2002. Unsuspected diversity among marine aerobic anoxygenic phototrophs. Nature 415:630-633. https:// doi.org/10.1038/415630a.

38. Yutin N, Suzuki MT, Teeling H, Weber M, Venter JC, Rusch DB, Béjà O. 2007. Assessing diversity and biogeography of aerobic anoxygenic phototrophic bacteria in surface waters of the Atlantic and Pacific Oceans using the Global Ocean Sampling expedition metagenomes. Environ Microbiol 9:1464-1475. https://doi.org/10.1111/j.1462-2920.2007.01265.x.

39. Matias MG, Combe M, Barbera C, Mouquet N. 2012. Ecological strategies shape the insurance potential of biodiversity. Front Microbiol 3:432. https://doi.org/10.3389/fmicb.2012.00432.

40. Šimek K, Horňak K, Jezbera J, Nedoma J, Vrba J, Straškrabova V, Macek M, Dolan JR, Hahn MW. 2006. Maximum growth rates and possible life strategies of different bacterioplankton groups in relation to phosphorus availability in a freshwater reservoir. Environ Microbiol 8:1613-1624. https://doi.org/10.1111/j.1462-2920.2006.01053.x.

41. Hahn MW. 2009. Description of seven candidate species affiliated with the phylum Actinobacteria, representing planktonic freshwater bacteria. Int J Syst Evol Microbiol 59:112-117. https://doi.org/10.1099/ijs.0 .001743-0.

42. Cabello-Yeves PJ, Zemskaya TI, Rosselli R, Coutinho FH, Zakharenko AS, Blinov VV, Rodriguez-Valera F. 2018. Genomes of novel microbial lineages assembled from the sub-ice waters of Lake Baikal. Appl Environ Microbiol 84:e02132-17. https://doi.org/10.1128/AEM.02132-17.

43. Kan J, Evans SE, Chen F, Suzuki MT. 2008. Novel estuarine bacterioplankton in rRNA operon libraries from the Chesapeake Bay. Aquat Microb Ecol 51:55-66. https://doi.org/10.3354/ame01177.

44. Ortmann AC, Santos TTL. 2016. Spatial and temporal patterns in the Pelagibacteraceae across an estuarine gradient. FEMS Microbiol Ecol 92:fiw133. https://doi.org/10.1093/femsec/fiw133.

45. Piwosz K, Salcher MM, Zeder M, Ameryk A, Pernthaler J. 2013. Seasonal dynamics and activity of typical freshwater bacteria in brackish waters of the Gulf of Gdańsk. Limnol Oceanogr 58:817-826. https://doi.org/10 .4319/lo.2013.58.3.0817.

46. Henson MW, Lanclos VC, Faircloth BC, Thrash JC. 2018. Cultivation and genomics of the first freshwater SAR11 (LD12) isolate. ISME J 12: 1846-1860. https://doi.org/10.1038/s41396-018-0092-2.

47. Zaremba-Niedzwiedzka K, Viklund J, Zhao W, Ast J, Sczyrba A, Woyke T, McMahon K, Bertilsson S, Stepanauskas R, Andersson SGE. 2013. Singlecell genomics reveal low recombination frequencies in freshwater bacteria of the SAR11 clade. Genome Biol 14:R130. https://doi.org/10.1186/ gb-2013-14-11-r130.

48. Eiler A, Mondav R, Sinclair L, Fernandez-Vidal L, Scofield DG, Schwientek P, Martínez-García M, Torrents D, McMahon KD, Andersson SG, Stepanauskas R, Woyke T, Bertilsson S. 2016. Tuning fresh: radiation through rewiring of central metabolism in streamlined bacteria. ISME J 10: 1902-1914. https://doi.org/10.1038/ismej.2015.260.

49. Elevi Bardavid R, Oren A. 2012. Acid-shifted isoelectric point profiles of the proteins in a hypersaline microbial mat: an adaptation to life at high salt concentrations? Extremophiles 16:787-792. https://doi.org/10.1007/ s00792-012-0476-6.

50. Jousset A, Bienhold C, Chatzinotas A, Gallien L, Gobet A, Kurm V, Küsel K, Rillig MC, Rivett DW, Salles JF, van der Heijden MGA, Youssef NH, 
Zhang X, Wei Z, Hol WHG. 2017. Where less may be more: how the rare biosphere pulls ecosystems strings. ISME J 11:853-862. https://doi.org/ 10.1038/ismej.2016.174.

51. Shade A, Jones SE, Caporaso JG, Handelsman J, Knight R, Fierer N, Gilbert JA. 2014. Conditionally rare taxa disproportionately contribute to temporal changes in microbial diversity. mBio 5:e01371-14. https://doi.org/ 10.1128/mBio.01371-14.

52. Lan Y, Rosen G, Hershberg R. 2016. Marker genes that are less conserved in their sequences are useful for predicting genome-wide similarity levels between closely related prokaryotic strains. Microbiome 4:18. https://doi.org/10.1186/s40168-016-0162-5.

53. Vishnivetskaya TA, Layton AC, Lau MCY, Chauhan A, Cheng KR, Meyers AJ, Murphy JR, Rogers AW, Saarunya GS, Williams DE, Pfiffner SM, Biggerstaff JP, Stackhouse BT, Phelps TJ, Whyte L, Sayler GS, Onstott TC. 2013. Commercial DNA extraction kits impact observed microbial community composition in permafrost samples. FEMS Microbiol Ecol 87: 217-230. https://doi.org/10.1111/1574-6941.12219.

54. Apprill A, McNally S, Parsons R, Weber L. 2015. Minor revision to V4 region SSU rRNA 806R gene primer greatly increases detection of SAR11 bacterioplankton. Aquat Microb Ecol 75:129-137. https://doi.org/10 .3354/ame01753.

55. Salter SJ, Cox MJ, Turek EM, Calus ST, Cookson WO, Moffatt MF, Turner P, Parkhill J, Loman NJ, Walker AW. 2014. Reagent and laboratory contamination can critically impact sequence-based microbiome analyses. BMC Biol 12:87. https://doi.org/10.1186/s12915-014-0087-z.

56. Wright ES, Vetsigian KH. 2016. Quality filtering of Illumina index reads mitigates sample cross-talk. BMC Genomics 17:876. https://doi.org/10 $.1186 / \mathrm{s} 12864-016-3217-x$.

57. Schloss PD, Westcott SL, Ryabin T, Hall JR, Hartmann M, Hollister EB, Lesniewski RA, Oakley BB, Parks DH, Robinson CJ, Sahl JW, Stres B, Thallinger GG, Van Horn DJ, Weber CF. 2009. Introducing mothur: opensource, platform-independent, community-supported software for describing and comparing microbial communities. Appl Environ Microbiol 75:7537-7541. https://doi.org/10.1128/AEM.01541-09.

58. Kozich JJ, Westcott SL, Baxter NT, Highlander SK, Schloss PD. 2013. Development of a dual-index sequencing strategy and curation pipeline for analyzing amplicon sequence data on the MiSeq Illumina sequencing platform. Appl Environ Microbiol 79:5112-5120. https://doi.org/10.1128/ AEM.01043-13.

59. Quast C, Pruesse E, Yilmaz P, Gerken J, Schweer T, Yarza P, Peplies J, Glockner FO. 2012. The SILVA ribosomal RNA gene database project: improved data processing and web-based tools. Nucleic Acids Res 41: D590-D596. https://doi.org/10.1093/nar/gks1219.

60. Yilmaz P, Parfrey LW, Yarza P, Gerken J, Pruesse E, Quast C, Schweer T, Peplies J, Ludwig W, Glöckner FO. 2014. The SILVA and "All-species Living Tree Project (LTP)" taxonomic frameworks. Nucleic Acids Res 42:D643-D648. https://doi.org/10.1093/nar/gkt1209.

61. Edgar RC, Haas BJ, Clemente JC, Quince C, Knight R. 2011. UCHIME improves sensitivity and speed of chimera detection. Bioinformatics 27:2194-2200. https://doi.org/10.1093/bioinformatics/btr381.

62. Love MI, Huber W, Anders S. 2014. Moderated estimation of fold change and dispersion for RNA-seq data with DESeq2. Genome Biol 15:550. https://doi.org/10.1186/s13059-014-0550-8.

63. Stamatakis A. 2014. RAxML version 8: a tool for phylogenetic analysis and post-analysis of large phylogenies. Bioinformatics 30:1312-1313. https://doi.org/10.1093/bioinformatics/btu033.

64. Paradis E, Claude J, Strimmer K. 2004. APE: analyses of phylogenetics and evolution in R language. Bioinformatics 20:289-290. https://doi.org/10 $.1093 /$ bioinformatics/btg412.

65. Letunic I, Bork P. 2016. Interactive tree of life (iTOL) v3: an online tool for the display and annotation of phylogenetic and other trees. Nucleic Acids Res 44:W242-W245. https://doi.org/10.1093/nar/gkw290.

66. McMurdie PJ, Holmes S. 2013. phyloseq: an R package for reproducible interactive analysis and graphics of microbiome census data. PLoS One 8:e61217. https://doi.org/10.1371/journal.pone.0061217.

67. Chen J, Bittinger K, Charlson ES, Hoffmann C, Lewis J, Wu GD, Collman RG, Bushman FD, Li H. 2012. Associating microbiome composition with environmental covariates using generalized UniFrac distances. Bioinformatics 28:2106-2113. https://doi.org/10.1093/bioinformatics/bts342.

68. Oksanen J, Blanchet FG, Friendly M, Kindt R, Legendre P, McGlinn D, Minchin PR, O'Hara RB, Simpson GL, Solymos P, Stevens MHH, Szoecs E,
Wagner H. 2016. vegan: community ecology package. $\mathrm{R}$ package version 2.4-1. https://CRAN.R-project.org/package= vegan.

69. Kembel SW, Cowan PD, Helmus MR, Cornwell WK, Morlon H, Ackerly DD, Blomberg SP, Webb CO. 2010. Picante: R tools for integrating phylogenies and ecology. Bioinformatics 26:1463-1464. https://doi.org/10 .1093/bioinformatics/btq166.

70. Sunagawa S, Coelho LP, Chaffron S, Kultima JR, Labadie K, Salazar G, Djahanschiri B, Zeller G, Mende DR, Alberti A, Cornejo-Castillo FM, Costea PI, Cruaud C, d'Ovidio F, Engelen S, Ferrera I, Gasol JM, Guidi L, Hildebrand F, Kokoszka F, Lepoivre C, Lima-Mendez G, Poulain J, Poulos BT, Royo-Llonch M, Sarmento H, Vieira-Silva S, Dimier C, Picheral M, Searson S, Kandels-Lewis S, Bowler C, de Vargas C, Gorsky G, Grimsley N, Hingamp $P$, ludicone D, Jaillon $O$, Not F, Ogata $H$, Pesant S, Speich $S$, Stemmann L, Sullivan MB, Weissenbach J, Wincker P, Karsenti E, Raes J, Acinas SG, Bork P, Boss E, Bowler C, Follows M, Karp-Boss L, Krzic U, Reynaud EG, Sardet C, Sieracki M, Velayoudon D. 2015. Ocean plankton. Structure and function of the global ocean microbiome. Science 348 : 1261359. https://doi.org/10.1126/science.1261359.

71. Benson DA, Karsch-Mizrachi I, Lipman DJ, Ostell J, Wheeler DL. 2005. GenBank. Nucleic Acids Res 33:D34-D38. https://doi.org/10.1093/nar/ gki063.

72. Buchfink B, Xie C, Huson DH. 2015. Fast and sensitive protein alignment using DIAMOND. Nat Methods 12:59-60. https://doi.org/10.1038/nmeth .3176 .

73. Ondov BD, Bergman NH, Phillippy AM. 2011. Interactive metagenomic visualization in a Web browser. BMC Bioinformatics 12:385. https://doi .org/10.1186/1471-2105-12-385.

74. Camacho C, Coulouris G, Avagyan V, Ma N, Papadopoulos J, Bealer K, Madden TL. 2009. BLAST+: architecture and applications. BMC Bioinformatics 10:421-429. https://doi.org/10.1186/1471-2105-10-421.

75. van Dongen S, Abreu-Goodger C. 2012. Using MCL to extract clusters from networks. Methods Mol Biol 804:281-295. https://doi.org/10.1007/ 978-1-61779-361-5_15.

76. Eren AM, Esen ÖC, Quince C, Vineis JH, Morrison HG, Sogin ML, Delmont TO. 2015. Anvi'o: an advanced analysis and visualization platform for 'omics data. PeerJ 3:e1319. https://doi.org/10.7717/peerj.1319.

77. Edgar RC. 2004. MUSCLE: multiple sequence alignment with high accuracy and high throughput. Nucleic Acids Res 32:1792-1797. https://doi .org/10.1093/nar/gkh340.

78. Matsen FA, Kodner RB, Armbrust EV. 2010. pplacer: linear time maximum-likelihood and Bayesian phylogenetic placement of sequences onto a fixed reference tree. BMC Bioinformatics 11:538. https:// doi.org/10.1186/1471-2105-11-538.

79. Logue JB, Langenheder S, Andersson AF, Bertilsson S, Drakare S, Lanzén A, Lindström ES. 2012. Freshwater bacterioplankton richness in oligotrophic lakes depends on nutrient availability rather than on speciesarea relationships. ISME J 6:1127-1136. https://doi.org/10.1038/ismej .2011.184.

80. Zhong Z-P, Liu Y, Miao L-L, Wang F, Chu L-M, Wang J-L, Liu Z-P. 2016. Prokaryotic community structure driven by salinity and ionic concentrations in plateau lakes of the Tibetan plateau. Appl Environ Microbiol 82:1846-1858. https://doi.org/10.1128/AEM.03332-15.

81. Peter H, Sommaruga R. 2016. Shifts in diversity and function of lake bacterial communities upon glacier retreat. ISME J 10:1545-1554. https://doi.org/10.1038/ismej.2015.245.

82. Schmidt ML, White JD, Denef VJ. 2016. Phylogenetic conservation of freshwater lake habitat preference varies between abundant bacterioplankton phyla. Environ Microbiol 18:1212-1226. https://doi.org/10 $.1111 / 1462-2920.13143$.

83. Linz AM, Crary BC, Shade A, Owens S, Gilbert JA, Knight R, McMahon KD. 2017. Bacterial community composition and dynamics spanning five years in freshwater bog lakes. mSphere 2:e00169-17. https://doi.org/10 .1128/mSphere.00169-17.

84. Mason OU, Canter EJ, Gillies LE, Paisie TK, Roberts BJ. 2016. Mississippi River plume enriches microbial diversity in the northern Gulf of Mexico. Front Microbiol 7:1048. https://doi.org/10.3389/fmicb.2016.01048.

85. Teeling H, Fuchs BM, Bennke CM, Krüger K, Chafee M, Kappelmann L, Reintjes G, Waldmann J, Quast C, Glöckner FO, Lucas J, Wichels A, Gerdts $\mathrm{G}$, Wiltshire $\mathrm{KH}, \mathrm{Amann}$ RI. 2016. Recurring patterns in bacterioplankton dynamics during coastal spring algae blooms. Elife 5:e11888. https://doi .org/10.7554/eLife.11888. 